\title{
A modified cascaded h-bridge multilevel inverter based on particle swarm optimisation (PSO) technique
}

\author{
Mohammed Rasheed ${ }^{1}$, Rosli Omar ${ }^{2}$, Marizan Sulaiman ${ }^{3}$, Wahidah Abd Halim ${ }^{4}$ \\ Faculty of Electrical Engineering, Universiti Teknikal Malaysia Melaka, Malaysia
}

\begin{tabular}{|c|c|}
\hline Article Info & ABSTRACT \\
\hline & \multirow{14}{*}{$\begin{array}{l}\text { In this paper, modified multilevel inverter, via addition of an auxiliary } \\
\text { bidirectional switch, based on Newton Raphson (NR) and Particle Swarm } \\
\text { Optimization (PSO) techniques is presented. The NR and PSO techniques } \\
\text { were employed for selective harmonics elimination (SHE) solution in a } \\
\text { modified Cascaded H Bridge Multilevel inverter (CHB-MLI). The Selective } \\
\text { Harmonic Elimination Pulse-Width Modulation (SHE-PWM) is a powerful } \\
\text { technique for harmonic minimization in multilevel inverter. The NR and PSO } \\
\text { techniques were used to determine the switching angles by solving the non- } \\
\text { linear equations of the output voltage waveform of the modified CHB-MLI } \\
\text { in order to control the fundamental component and eliminate some low order } \\
\text { harmonics. The proposed NR and PSO techniques are capable to minimize } \\
\text { the Total Harmonic Distortion (THD) of the output voltage of the modified } \\
\text { inverter within allowable limits. This paper aims to modeling and simulation } \\
\text { by MATLAB of the modified topology of the CHB-MLI for a single-phase } \\
\text { prototype for 13-levels. The inverter offers less THD and greater efficiency } \\
\text { using PSO control algorithm compared with the NR algorithm. } \\
\text { The performance of the proposed controllers based on NR and PSO } \\
\text { techniques is verified through simulation. }\end{array}$} \\
\hline Received Jan 23, 2019 & \\
\hline Revised Apr 25, 2019 & \\
\hline Accepted May 16, 2019 & \\
\hline & \\
\hline Keywords: & \\
\hline 13-level & \\
\hline Harmonics & \\
\hline Inverters & \\
\hline Modified multilevel & \\
\hline PSO & \\
\hline & \\
\hline & \\
\hline & \\
\hline
\end{tabular}

Copyright @ 2019 Institute of Advanced Engineering and Science. All rights reserved.

\section{Corresponding Author:}

Mohammed Rasheed,

Faculty of Electrical Engineering,

Universiti Teknikal Malaysia Melaka,

Industrial Power, 76100, Hang Tuah Jaya, Durian Tunggal, Melaka, Malaysia.

Email: rasheed@utem.edu.my

\section{INTRODUCTION}

Multilevel power conversion was first introduced 25 years ago [1]. The general concept involves utilizing a higher number of active semiconductor switches to perform the power conversion in small voltage steps. There are several advantages to this approach when compared with traditional two-level power conversion. The smaller voltage steps lead to the production of higher power quality waveforms and also reduce the $\mathrm{dv} / \mathrm{dt}$ stresses on the load and the electromagnetic compatibility concerns. Another important feature of multilevel converters is that the semiconductors are wired in a series-type connection, which allows operation at higher voltages. However, the series connection is typically made with clamping diodes, which eliminate over voltage concerns. Furthermore, since the switches are not truly series connected, their switching can be staggered, which reduces the switching frequency and thus the switching losses [2, 3]. The harmonic elimination techniques are utilized in multilevel inverters in order to lower harmonic content for improving the output waveform of the voltage inverter, reduce the size of the filter utilized and the level of electromagnetic interference (EMI). Numerous topologies can be used to realize those advantages and can generally be divided into three major categories, namely, diode clamped multilevel inverter DC-MLI, flying capacitor multilevel inverter FC-MLI and separated DC sources cascaded H-bridge CHB-MLI. The type of the MLI which uses a single DC source rather than multiple sources is called the diode-clamped MLI. While, the FC type is designed by series connection of capacitor clamped switching 
cells. The CHB switches are connected in parallel and series in order to provide high power demand and high-power quality [4-10], [11, 12] Reduced number of switches with installation area and cost as well as simplicity of control system, with a high number of steps associated using a new topology of cascaded multilevel inverter (CHB-MLI) has been presented in [13]. A new topology for current source multilevel inverter (CSI) with reduced number of switches to generate desired output current based on sinusoidal pulse width modulation (SPWM) method has been presented in [14]. This topology employs $(n+7) / 2$ switches and $(n-1) / 2$ current-sharing inductors for an n-level CSI.A 5-level single-phase inverter has been developed by field-programmable gate array (FPGA) by [15]. The digital control technique is generated based on multi carrier PWM in Altera DE2 board, which has many features that implement the system design the simulation and experimental results have been consistent. A seven-level inverter has been simulated by [16] via implementation of PWM techniques to reduce total harmonic distortion (THD). This inverter is implemented on the principle of reducing numbers of switches, thus decreasing number of gate drivers in the circuit. The simulation circuitry basically incorporates DC supply and smaller (CHB-MLI) blocks connected in series to implement its desired stepped output waveform.

In this paper, a modified CHB-MLI based on auxiliary bidirectional switch controlled using NR and PSO techniques for optimisation of the output with 13-levels is implemented based on MATLAB Simulink. Most of the researchers had applied the PSO technique to the single phase conventional CHB-MLIs. The NR and PSO techniques are used to calculate switching angles with the capability to eliminate harmonics in the output of the modified CHB-MLIs. Finally, in this paper, is evaluated and validated through simulation results.

\section{SWITCHING OPERATION MODES OF MODIFIED CHB-MLIS FOR 13-LEVELS}

The switching mode operation of the proposed single-phase modified CHB-MLI for 13-levels can be illustrated in Figure 1. As previously mentioned, the proposed topology adopts a full-bridge configuration with an auxiliary circuit comprising four diodes and a switch which generates half-level DC bus voltage. Figure 2 shows the timing diagram or switching pattern for all switches employed in the modified CHB-MLI. The output voltages of the modified CHBMLI for 13 levels can be summarized as described in Table 1 . The present work presents a 13-level PWM inverter with output voltages $\mathrm{Vdc}, \mathrm{Vdc} / 2, \mathrm{Vdc} / 3, \mathrm{Vdc} / 4,0$, $\mathrm{Vdc} / 4,-\mathrm{Vdc} / 3,-\mathrm{Vdc} / 2$ and $-\mathrm{Vdc}$. Surely that increasing the number of output levels of an inverter would reduce its harmonic content.

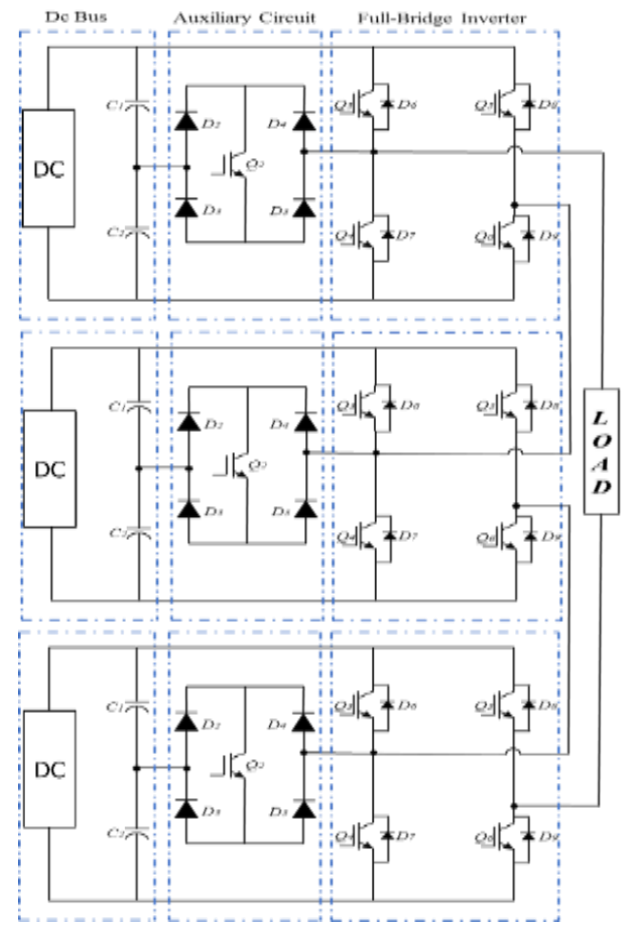

Figure 1. Proposal of modified CHB-MLI, single-phase 13-level topology

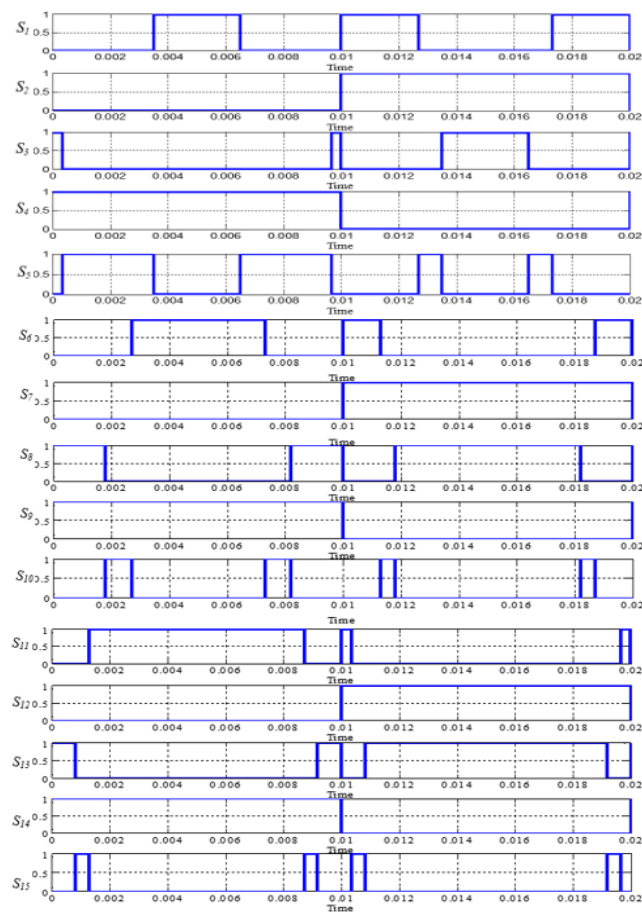

Figure 2. Switching pattern of modified CHB-MLIs for 13-levels 
Table 1. Output Voltage for 13-level Inverter to the Switches' states On=1 and Off $=0$

\begin{tabular}{ccccccccccccccccc}
\hline Voltage State & $\mathrm{S}_{1}$ & $\mathrm{~S}_{2}$ & $\mathrm{~S}_{3}$ & $\mathrm{~S}_{4}$ & $\mathrm{~S}_{5}$ & $\mathrm{~S}_{6}$ & $\mathrm{~S}_{7}$ & $\mathrm{~S}_{8}$ & $\mathrm{~S}_{9}$ & $\mathrm{~S}_{10}$ & $\mathrm{~S}_{11}$ & $\mathrm{~S}_{12}$ & $\mathrm{~S}_{13}$ & $\mathrm{~S}_{14}$ & $\mathrm{~S}_{15}$ & $\mathrm{~V}_{0}$ \\
\hline $\mathrm{A}$ & 1 & 0 & 0 & 1 & 0 & 1 & 0 & 0 & 1 & 0 & 1 & 0 & 0 & 1 & 0 & $\mathrm{Vdc}$ \\
$\mathrm{B}$ & 1 & 0 & 0 & 1 & 0 & 1 & 0 & 0 & 1 & 0 & 0 & 0 & 0 & 1 & 1 & $\mathrm{~V}_{\mathrm{dc}} / 2$ \\
$\mathrm{C}$ & 0 & 1 & 1 & 0 & 0 & 0 & 0 & 0 & 1 & 1 & 0 & 0 & 0 & 1 & 1 & $\mathrm{~V}_{\mathrm{dc}} / 3$ \\
$\mathrm{D}$ & 0 & 0 & 0 & 1 & 1 & 0 & 0 & 0 & 1 & 1 & 0 & 0 & 0 & 1 & 1 & $\mathrm{~V}_{\mathrm{dc}} / 4$ \\
$\mathrm{E}$ & 0 & 0 & 0 & 1 & 1 & 0 & 0 & 0 & 1 & 1 & 0 & 0 & 1 & 1 & 0 & $\mathrm{~V}_{\mathrm{dc}} / 5$ \\
$\mathrm{~F}$ & 0 & 0 & 0 & 1 & 1 & 0 & 0 & 1 & 1 & 0 & 0 & 0 & 1 & 1 & 0 & $\mathrm{~V}_{\mathrm{dc}} / 6$ \\
$\mathrm{G}$ & 0 & 0 & 1 & 1 & 0 & 0 & 0 & 1 & 1 & 0 & 0 & 0 & 1 & 1 & 0 & 0 \\
$\mathrm{H}$ & 1 & 1 & 0 & 0 & 0 & 1 & 1 & 0 & 0 & 0 & 1 & 1 & 0 & 0 & 0 & $0 *$ \\
$\mathrm{I}$ & 0 & 1 & 0 & 0 & 1 & 1 & 1 & 0 & 0 & 0 & 1 & 1 & 0 & 0 & 0 & $-\mathrm{V}_{\mathrm{dc}} / 6$ \\
$\mathrm{~J}$ & 0 & 1 & 0 & 0 & 1 & 0 & 1 & 0 & 0 & 0 & 1 & 1 & 0 & 0 & 0 & $-\mathrm{V}_{\mathrm{dc}} / 5$ \\
$\mathrm{~K}$ & 0 & 1 & 0 & 0 & 1 & 0 & 1 & 0 & 0 & 1 & 0 & 1 & 0 & 0 & 1 & $-\mathrm{V}_{\mathrm{dc}} / 4$ \\
$\mathrm{~L}$ & 0 & 1 & 1 & 0 & 0 & 0 & 1 & 0 & 0 & 1 & 0 & 1 & 0 & 0 & 1 & $-\mathrm{V}_{\mathrm{dc}} / 3$ \\
$\mathrm{M}$ & 0 & 1 & 1 & 0 & 0 & 0 & 1 & 1 & 0 & 0 & 0 & 1 & 0 & 0 & 1 & $-\mathrm{V}_{\mathrm{dc}} / 2$ \\
$\mathrm{~N}$ & 0 & 1 & 1 & 0 & 0 & 0 & 1 & 1 & 0 & 0 & 0 & 1 & 1 & 0 & 0 & $-\mathrm{Vddc}^{2}$ \\
\hline
\end{tabular}

\section{ANALYSIS OF THE PROPOSED TOPOLOGIES OF THE MODIFIED CHB-MLI FOR 13-}

\section{LEVELS}

A. Fourier Series for the Output Voltage of the Proposed Modified CHB-MLI for 13-Level:

The equations for 13-levels based on the Fourier series are described below [20]:

$$
\begin{aligned}
& f(t)=f_{\theta 1}(t)+f_{\theta 2}(t)+f_{\theta 3}(t)+f_{\theta 4}(t)+f_{\theta 5}(t)+f_{\theta 6}(t) \\
& \quad=\sum_{n=1,3,5}^{\infty} \frac{2 V_{d c}}{n \pi}\left[\left(V_{d c 1} \cos \left(n \theta_{1}\right)+V_{d c 2} \cos \left(n \theta_{2}\right)+V_{d c 3} \cos \left(n \theta_{3}\right)+V_{d c 4} \cos \left(n \theta_{4}\right)+V_{d c 5} \cos \left(n \theta_{5}\right)+\right.\right. \\
& \left.V_{d c 6} \cos \left(n \theta_{6}\right)\right] \sin (n w t)
\end{aligned}
$$

where:

$V_{d c i}$ : Voltage of each voltage source that was in unity

$\theta_{i}:$ Switching angles

$i=1,2 \ldots 6$.

From (1), six equations were resulted, one for controlling the fundamental component $1^{\text {st }}$ and others for eliminating the $3^{\text {th }}, 5^{\text {th }}, 7^{\text {th }}, 9^{\text {th }}$ and $11^{\text {th }}$ harmonics.

$V_{A N}=V_{d c 1}+V_{d c 2}+V_{d c 3}$

$b_{n}=\frac{2 V_{d c}}{n \pi}\left\{\cos \left(n \theta_{1}\right)+\cos \left(n \theta_{2}\right)+\cos \left(n \theta_{3}\right)+\cos \left(n \theta_{4}\right)+\cos \left(n \theta_{5}\right)+\cos \left(n \theta_{6}\right)\right\} n=1,3,5,7$,

As shown in (2) has six variables $\left(\theta_{1}, \theta_{2}, \theta_{3}, \ldots, \theta_{6}\right)$, where $0<\theta_{1}<\theta_{2}<\theta_{3} \ldots<\theta_{6}<\pi / 2$, and a solution set is obtained by assigning a specific value to the fundamental component, $V_{f}$, and equating the remaining equations to zero as given below:

$$
\begin{aligned}
& V_{1} \cos \left(\theta_{1}\right)+V_{2} \cos \left(\theta_{2}\right)+V_{3} \cos \left(\theta_{3}\right)+V_{4} \cos \left(\theta_{4}\right)+V_{5} \cos \left(\theta_{5}\right)+V_{6} \cos \left(\theta_{6}\right)=6 m_{i} \\
& V_{1} \cos \left(3 \theta_{1}\right)+V_{2} \cos \left(3 \theta_{2}\right)+V_{3} \cos \left(3 \theta_{3}\right)+V_{4} \cos \left(3 \theta_{4}\right)+V_{5} \cos \left(3 \theta_{5}\right)+V_{6} \cos \left(3 \theta_{6}\right)=0 \\
& V_{1} \cos \left(5 \theta_{1}\right)+V_{2} \cos \left(5 \theta_{2}\right)+V_{3} \cos \left(5 \theta_{3}\right)+V_{4} \cos \left(5 \theta_{4}\right)+V_{5} \cos \left(5 \theta_{5}\right)+V_{6} \cos \left(5 \theta_{6}\right)=0 \\
& V_{1} \cos \left(7 \theta_{1}\right)+V_{2} \cos \left(7 \theta_{2}\right)+V_{3} \cos \left(7 \theta_{3}\right)+V_{4} \cos \left(7 \theta_{4}\right)+V_{5} \cos \left(7 \theta_{5}\right)+V_{6} \cos \left(7 \theta_{6}\right)=0 \\
& V_{1} \cos \left(9 \theta_{1}\right)+V_{2} \cos \left(9 \theta_{2}\right)+V_{3} \cos \left(9 \theta_{3}\right)+V_{4} \cos \left(9 \theta_{4}\right)+V_{5} \cos \left(9 \theta_{5}\right)+V_{6} \cos \left(9 \theta_{6}\right)=0 \\
& V_{1} \cos \left(11 \theta_{1}\right)+V_{2} \cos \left(11 \theta_{2}\right)+V_{3} \cos \left(11 \theta_{3}\right)+V_{4} \cos \left(11 \theta_{4}\right)+V_{5} \cos \left(11 \theta_{5}\right)+V_{6} \cos \left(11 \theta_{6}\right)=0
\end{aligned}
$$

where $m=\mathrm{V}_{1} /\left(2 V_{d c} / \pi\right)$, and it is related to the modulation index $m_{i}$ by $m_{i}=m / s$, where $0<m_{i}<1$.

An objective function is then needed for the optimisation procedure selected as a measure of effectiveness of eliminating selected order of harmonics while maintaining the fundamental component at a pre-specified value. Therefore, this function is defined as:

$$
F\left(\theta_{1}, \theta_{2}, \ldots, \theta_{s}\right)=\left[\sum_{\mathrm{n}=1}^{\mathrm{s}} \mathrm{V}_{1} \cos \left(\theta_{\mathrm{n}}\right)-\mathrm{m}\right]^{2}+\left[\sum_{\mathrm{n}=1}^{\mathrm{s}} \mathrm{V}_{2} \cos \left(3 \theta_{\mathrm{n}}\right)\right]^{2}+\ldots\left[\sum_{\mathrm{n}=1}^{\mathrm{s}} \mathrm{V}_{\mathrm{s}} \cos (2 s-1) \theta_{\mathrm{s}}\right]^{2}
$$

The optimal switching angles are obtained by minimising (4) subjected to the constraint 0 $<\theta_{1}<\theta_{2}<\theta_{3}<\theta_{4}=\ldots<\theta_{\mathrm{s}}<\pi / 2$, and consequently the required harmonic profile is achieved. The main challenge is the non-linearity of the transcendental set of (4), as most iterative techniques can be used with five and 13levels of the modified CHB-MLI as shown in Figure 3 and each step is explained, General flowchart of the PSO of the modified CHB-MLI as shown in Figure 4. 


\subsection{NR Technique}

The values of the switching angles $\theta_{1}, \theta_{2}, \theta_{3}, \theta_{4}, \theta_{5}$, and $\theta_{6}$ can be chosen by solving the transcendental equations using a modulation index formula (5) to obtain the suitable.

$$
m i=\frac{\pi \mathrm{V} f}{2 V_{d c}}(0 \leq m i \leq 1)
$$

Where, mi is the modulation index

For the angles $\theta_{7}$ until $\theta_{24}$ can be obtained by referring the output waveform of 13-levels of the modified CHB-MLIs theory in Figure 5. The procedure of detecting attributes and configuration of a system is called optimisation. For a 13-level single phase inverter, only five harmonics can be eliminated which are the $3^{\text {rd }}, 5^{\text {th }}, 7^{\text {th }}$, $9^{\text {th }}$, and $11^{\text {th }}$ harmonics. Thus, the switching angles can be found by solving the transcendental equations by using NR technique. These switching angles are then examined for their corresponding THD given by:

$$
T H D_{V}=\frac{\sqrt{\sum_{n=1}^{\infty} V_{n}^{2}}}{V_{1}}
$$

The effect of optimised angles for 13-levels are $\alpha_{1}, \alpha_{2}, \alpha_{3}, \alpha_{4}, \alpha_{5}, \alpha_{6}$, on the THD and the modulation index. By using MATLAB coding for number of iterations, it can be easily find that the modulation index is equal to 0.949 and the corresponding THD value of output voltage with 13-levels is equal to $6.18 \%$.

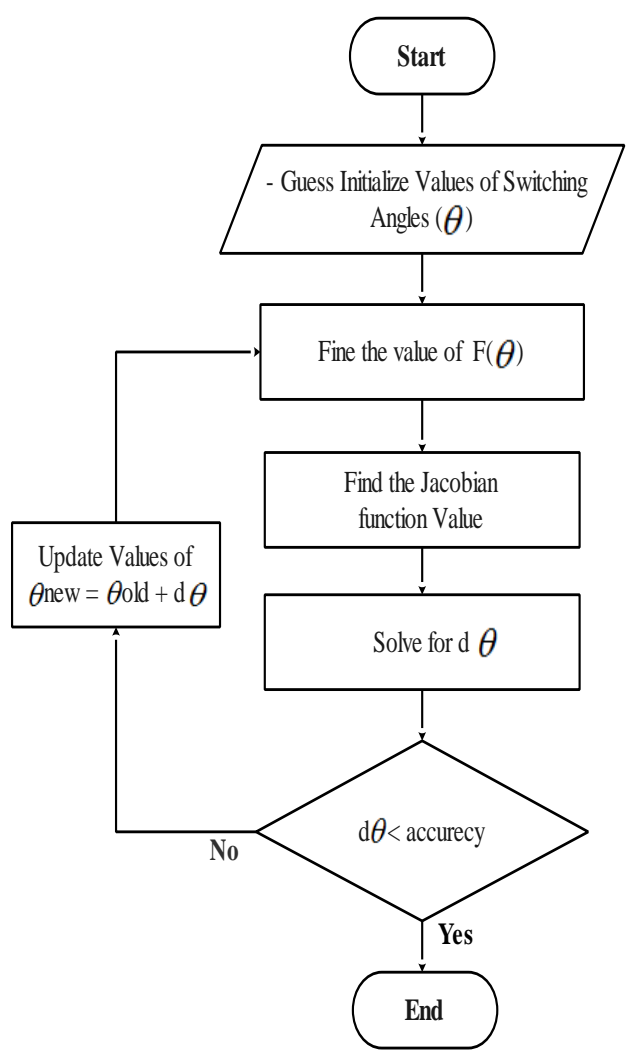

Figure 3. General flow-chart of NR of the modified CHB-MLIs

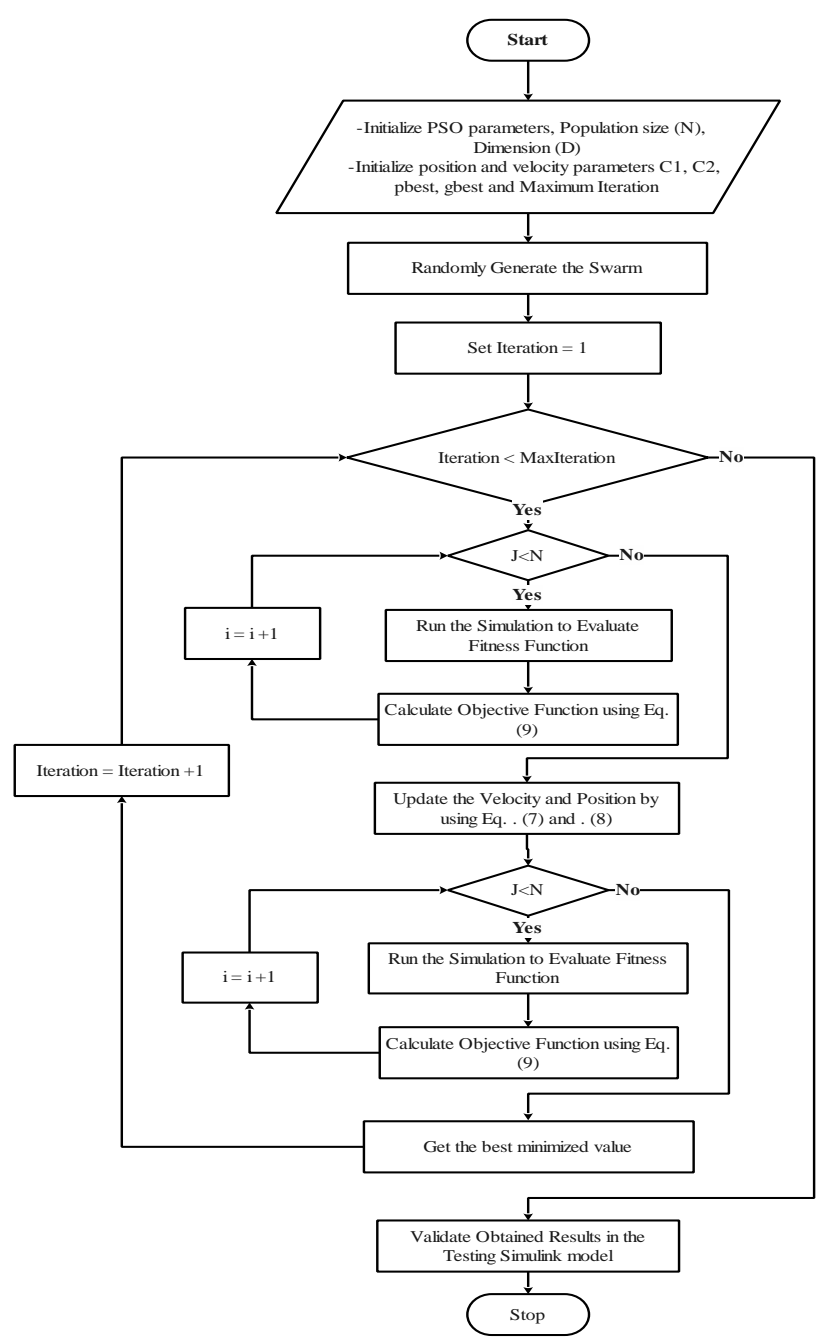

Figure 4. General flowchart of the PSO of the modified CHB-MLI 


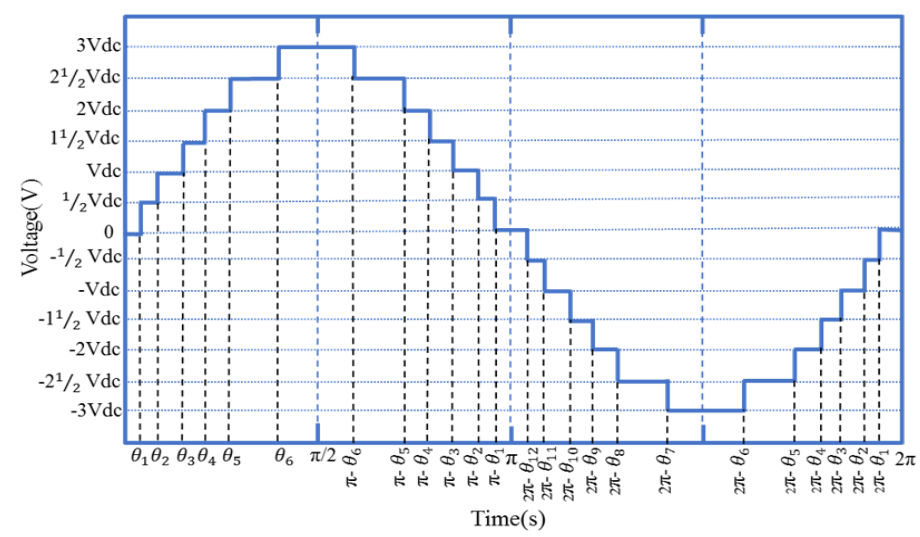

Figure 5. $\mathrm{V}_{\mathrm{ab}}$ at low switching frequency of modified CHB-MLI, for 13-levels

\subsection{PSO Technique}

PSO has become a very popular technique in solving non-linear optimization problems. Among many types of evolutionary algorithms, particle swarm is preferred primarily because of its computational efficiency, simplicity and ability to avoid local optima. The PSO has the following key advantages over other evolutionary optimization techniques [17-20]. The PSO algorithm is required to solve nonlinear equations based on SHE algorithm for solving the transcendental equations in order to optimize best switching angles. The number of iteration in the algorithm is solved using MATLAB coding to get better angles for eliminating specific unwanted harmonics. The iteration PSO algorithm can be described by the following steps:

Step 1: Initialise the system parameters such as velocity vector $\mathrm{Vi}$, location vector $\mathrm{Xi}$, personal best particle vector $\mathrm{Pi}$, particle inertia weight $\mathrm{C} 0$, and global best vector Pg. Assign the values of generations as 100, population size as 40, cognitive parameter $\mathrm{C} 1$ as 0.5 and social parameter $\mathrm{C} 2$ as 1.25 .

Step 2: Check for the case $0<(\mathrm{C} 1+\mathrm{C} 2)<2$ and $(\mathrm{C} 1+\mathrm{C} 2) / 2<\mathrm{C} 0<1$, if the two cases are satisfied then the system will be guaranteed to converge to a stable equilibrium point. If false, go to Step 1.

Step 3: Update the Velocity, Vi $(t+1)$.

$$
\operatorname{Vij}(\mathrm{t}+1)=\mathrm{Vi}(\mathrm{t})+\gamma_{1 i}\left(\mathrm{P}_{i}-\mathrm{x}_{i}(t)\right)+\gamma_{2 i}\left(\mathrm{G}_{i}-\mathrm{x}_{i}(t)\right)
$$

Step 4: Update the Position, $\mathrm{Xi}(\mathrm{t}+1)$.

$$
\mathrm{Xij}(\mathrm{t}+1)=\mathrm{Xij}(\mathrm{t})+\mathrm{Vij}(\mathrm{t}+1)
$$

where $\mathrm{i}$ is the particle index, $\mathrm{j}$ is the index of parameter of concern to be optimized, $\mathrm{x}$ is the position of the ith particle and jth parameter, $\mathrm{k}$ is the discrete time index, $\mathrm{V}$ is the velocity of the ith particle and jth parameter, $\mathrm{P}$ is the best position found by the ith particle and jth parameter (personal best), $G$ is the best position found by swarm (global best), $\mathrm{C}$ is a random uniform number between $[0,1]$ applied to the ith particle.

Step 5: Now, utilize the Fitness Function in order to evaluate the particle,

Here the switching angles $\alpha_{1}, \alpha_{2}, \alpha_{3}, \alpha_{4}, \alpha_{5}$, and $\alpha_{6}$ are chosen in such a way that the selective harmonics $3^{\text {th }}, 5^{\text {th }}$, $7^{\text {th }}, 9^{\text {th }}$, and $11^{\text {th }}$ are eliminated. The corresponding transcendental equations are given by:

$\mathrm{F}(1)=\left(\cos \left(\theta_{1}\right)+\cos \left(\theta_{2}\right)+\cos \left(\theta_{4}\right)+\cos \left(\theta_{4}\right)+\cos \left(\theta_{5}\right)+\cos \left(\theta_{6}\right)\right)-$ ma.

$\mathrm{F}(2)=\left(\cos \left(3 * \theta_{1}\right)+\cos \left(3 * \theta_{2}\right)+\cos \left(3 * \theta_{3}\right)+\cos \left(3 * \theta_{4}\right)+\cos \left(3 * \theta_{5}\right)+\cos \left(3 * \theta_{6}\right)\right)$.

$\mathrm{F}(3)=\left(\cos \left(5 * \theta_{1}\right)+\cos \left(5 * \theta_{2}\right)+\cos \left(5 * \theta_{3}\right)+\cos \left(5 * \theta_{4}\right)+\cos \left(5 * \theta_{5}\right)+\cos \left(5 * \theta_{6}\right)\right)$.

$\mathrm{F}(4)=\left(\cos \left(7 * \theta_{1}\right)+\cos \left(7 * \theta_{2}\right)+\cos \left(7 * \theta_{3}\right)+\cos \left(7 * \theta_{4}\right)+\cos \left(7 * \theta_{5}\right)+\cos \left(7 * \theta_{6}\right)\right)$.

$\mathrm{F}(5)=\left(\cos \left(9 * \theta_{1}\right)+\cos \left(9 * \theta_{2}\right)+\cos \left(9 * \theta_{3}\right)+\cos \left(9 * \theta_{4}\right)+\cos \left(9 * \theta_{5}\right)+\cos \left(9 * \theta_{6}\right)\right)$.

$\mathrm{F}(6)=\left(\cos \left(11 * \theta_{1}\right)+\cos \left(11 * \theta_{2}\right)+\cos \left(11 * \theta_{3}\right)+\right.$

$$
\left.\cos \left(11 * \theta_{4}\right)+\cos \left(11 * \theta_{5}\right)+\cos \left(11 * \theta_{6}\right)\right)
$$

Step 6: Check the constraints $0 \leq \theta_{1} \leq \theta_{2} \leq \theta_{3} \leq \theta_{4} \leq \theta_{5} \leq \theta_{6} \leq \pi / 2$.

Step 7: Check for the case $\mathrm{P}(\mathrm{xi})<\mathrm{P}(\mathrm{Pi})$, if $\mathrm{i}=\mathrm{i}+1$ not satisfied then execute to Step 3 .

Step 8: If the produced location of the particle is the best then update by change with the previous location as $\mathrm{Pi}$ $=\mathrm{Xi}$.

Step 9: Update the global best location as $\mathrm{Pg}=\min (\mathrm{P}$ neighbor).

Step10: Switching angles are optimized as the best. Accomplish the solution of the problem.

The general flowchart of the PSO of the modified CHB-MLI is shown in Figure 5. 


\section{MODELLING OF THE PROPOSED MODIFIED CHB-MLI}

MATLAB/SIMULINK software was used to model the proposed topologies of the modified CHB-MLI for 13, levels. Figure 6 shows the circuit diagram of the proposed single-phase modified CHB-MLI for 13-levels. The configuration of this model consists of conventional inverter with 12 switches in addition to a 3-bi-directional switch. This paper aims to develop a PSO algorithm based on the SHE technique for getting the best firing angles for harmonics elimination and compare it with the conventional NR algorithm. The system operation was simulated at low switching frequency. In this simulation, the model, has three DC supply of $300 \mathrm{~V}$ each. Generator pulse block is used to procedure the switching pattern for generating switching pulses necessary to control the switches of the MLI based on the NR and PSO algorithms. A resistor of $100 \mathrm{k} \Omega$ will be used as a load to the proposed inverter model. The maximum output phase voltage of the modified CHB-MLI is 900 volts with frequency of $50 \mathrm{~Hz}$. The series connected DC bus capacitors $\mathrm{C} 1$ and $\mathrm{C} 2$ ere $2500 \mathrm{e}-6 \mathrm{~F}$, which split the DC bus voltage for each cell into: $\mathrm{V}_{\mathrm{DC}} / 2,0,-\mathrm{V}_{\mathrm{DC}} / 2$. The middle point $\mathrm{n}$ of the capacitors is defined as the neutral point.

\section{SIMULATION RESULTS OF MODIFIED CHB-MLI FOR 13-LEVELS WITH $m_{i}=0.81$ USING NR AND PSO ALGORITHMS}

In order to obtain the optimization of the output of the single-phase modified CHB-MLI with 13-levels, the switching angles based on the NR and PSO algorithms were calculated. Based on the simulation model, Figure 7, Figure 8 and Figure 9 show the timing diagram of the switches in the single-phase modified CHB-MLI of 13-levels. There are 3 cells available in the configuration of the proposed inverter shown in the methodology of Figure 6.

Each cell comprises five switches, including bi-directional switch, namely e.g. for the first cell has the switches S1, S2, S3, and S4 and the bi-directional switch S5. From these figures, it is noted that the 15 switches have equal switching periods using a switching frequency of $2500 \mathrm{~Hz}$. The switching angles of the inverter were calculated using the NR technique with MATLAB code and the obtained switching angles are equal to $\theta_{1}=6.2542^{\circ}$, $\theta_{2}=14.3224^{\circ}, \theta_{3}=22.9152^{\circ}, \theta_{4}=32.044^{\circ}, \theta_{5}=48.0239^{\circ}$, and $\theta_{6}=62.6458^{\circ}$. These angles have used the SHE based on the NR technique in order to generate the output of the inverter waveform with time period of $0.02 \mathrm{~s}$, and $m_{i}$ equal to 0.81 .
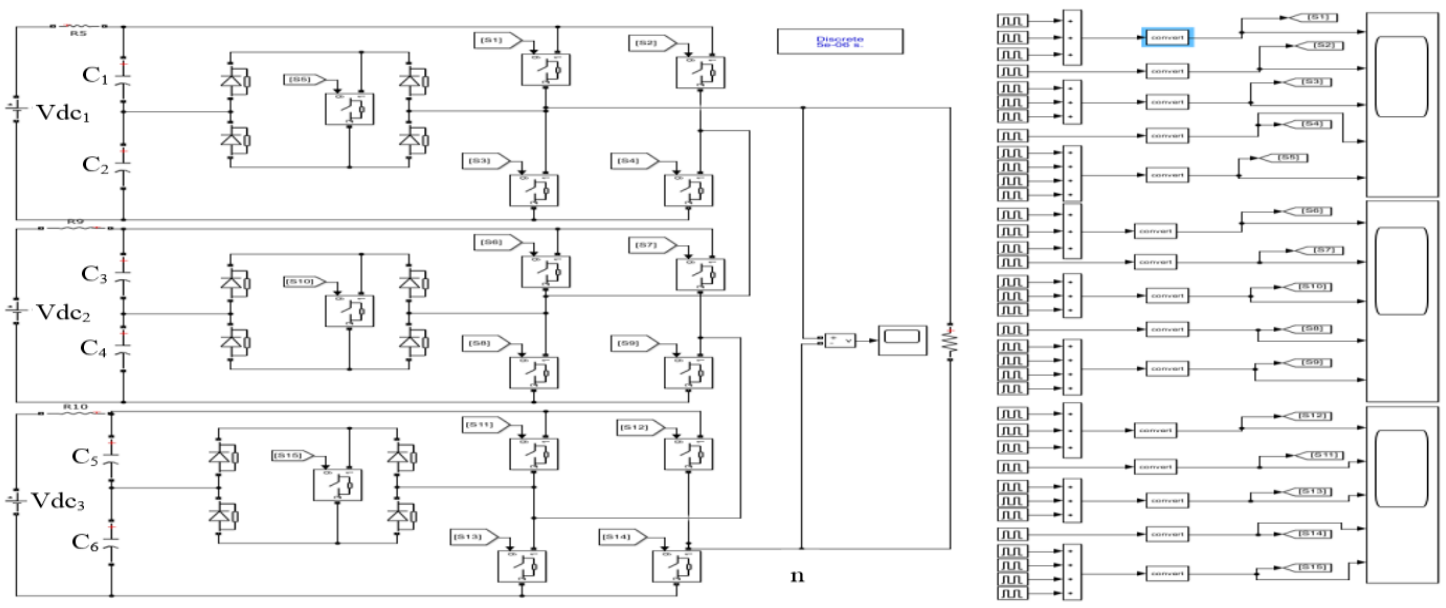

Figure Error! No text of specified style in document.6. Simulations of modified CHB-MLIs for 13-levels model

The obtained timing diagram for the optimization of output voltage waveform of the single-phase 13level modified CHB-MLI using the NR technique has been produced as shown in Figure Error! No text of specified style in document.10. In order to eliminate the specific order harmonics of the inverter output, the SHE technique of the fundamental switching frequency scheme is used. In this paper, the single-phase modified CHB-MLI with equal DC sources based on the super capacitors $[18,19]$ is utilized. The output voltage harmonic spectra of the single-phase modified CHB-MLI using the NR were obtained through simulation as shown in Figure Error! No text of specified style in document.11. Figure Error! No text of specified style in document.11 shows the THDv value of the modified inverter output voltage-which equivalent to $6.59 \%$.

The simulation results of timing diagram of the single-phase 13-level modified CHB-MLI based on the PSO technique can be shown in Figure Error! No text of specified style in document.12, Figure Error! No 
text of specified style in document.13 and Figure Error! No text of specified style in document.14. The optimized switching angles obtained by using MATLAB simulation are equal to $\theta_{1}=4.4873^{0}, \theta_{2}=14.5441^{0}$, $\theta_{3}=24.5761^{0}$, $\theta_{4}=33.1991^{0}$,

$\theta_{5}=45.82^{0}$,

and $\theta_{6}=62.672^{0}$.

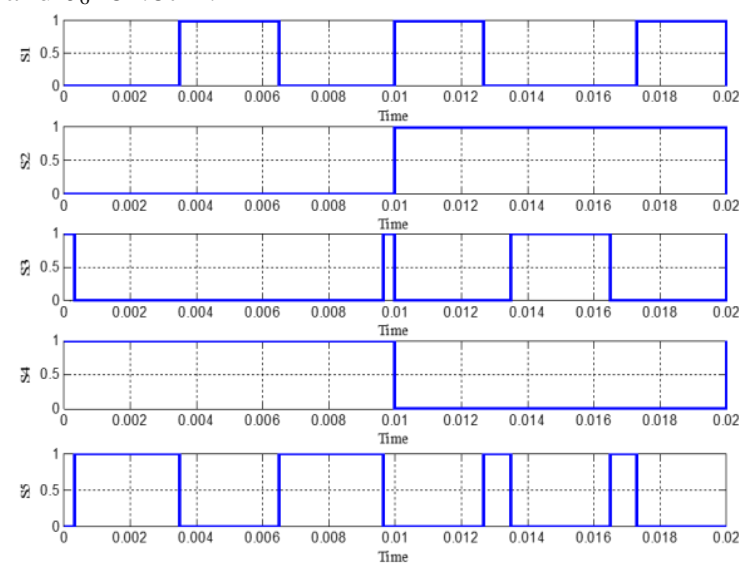

Figure 7. Timing diagram for cell 1 in 13 level inverter comprising S1-S5 switches with $\mathrm{mi}=0.81$ using NR technique
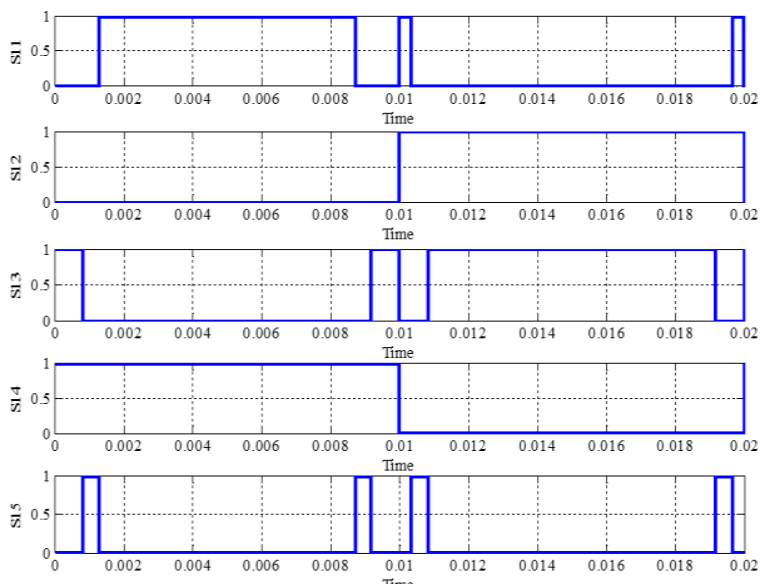

Figure 9. Timing diagram for cell 3 in 13 level inverter comprising S11-S15 switches with $\mathrm{mi}=0.81$ using NR technique

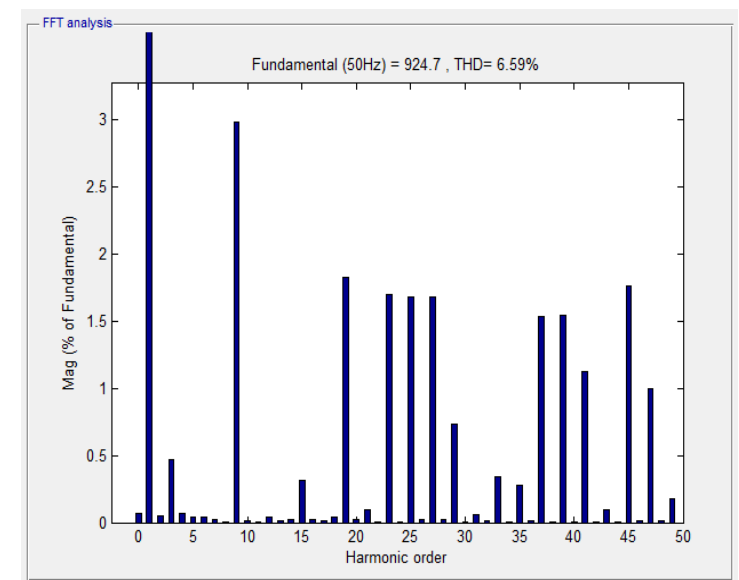

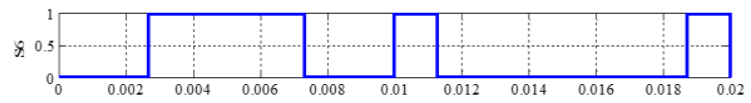
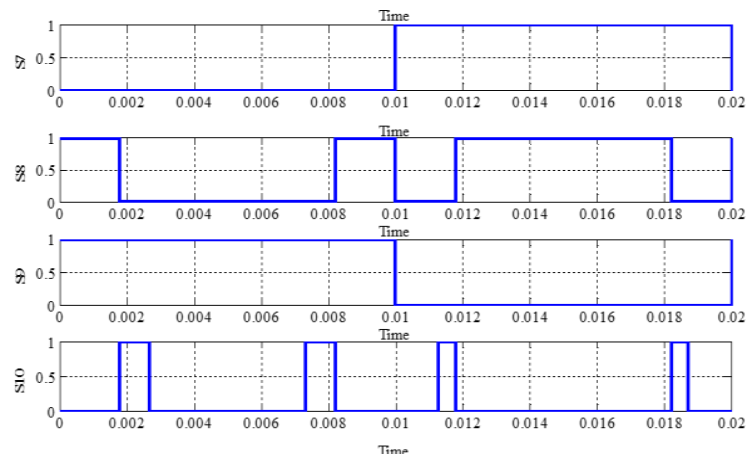

Figure 8. Timing diagram for cell 2 in 13 level inverter comprising S6-S10 switches with $\mathrm{mi}=0.81$ using NR technique

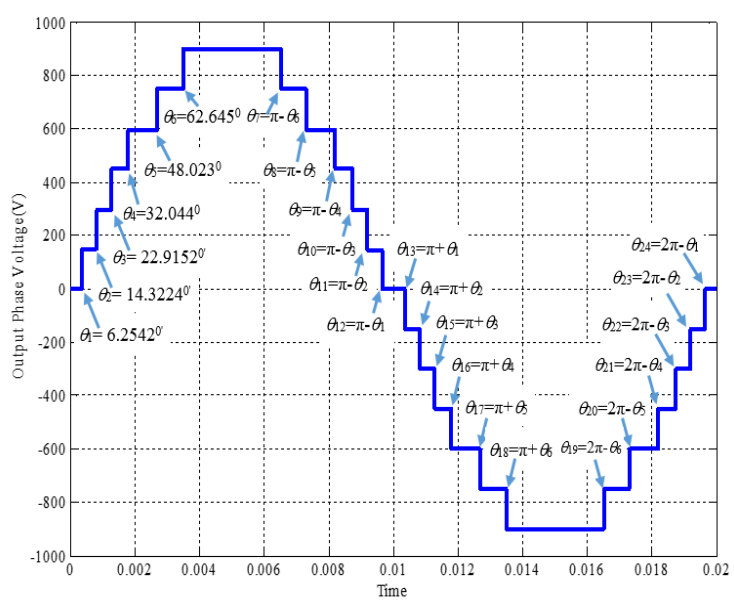

Figure 10. The optimization of output voltage waveform of the modified 13-level inverter with $\mathrm{mi}=0.81 \mathrm{using}$ NR technique
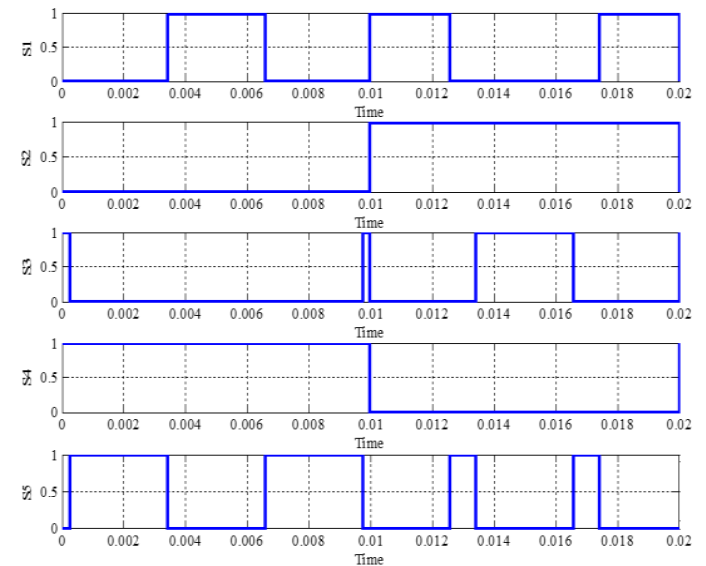
Figure 11. Harmonic spectrum of output voltage waveform of the modified CHB-MLI with mi $=0.81$ using NR technique
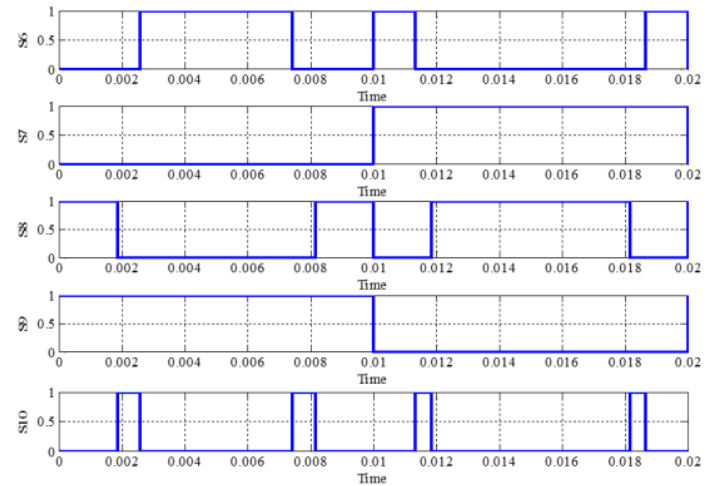

Figure 13. Timing diagram for cell 2 in 13 level inverter comprising S6-S10 switches with $\mathrm{mi}=0.81$ using PSO technique
Figure 12. Timing diagram for cell 1 in 13 level inverter comprising S1-S5 switches with $\mathrm{mi}=0.81$ using PSO technique
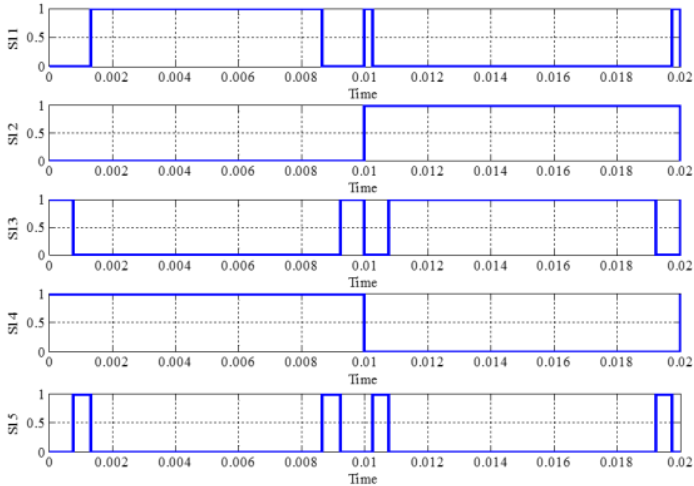

Figure 14. Timing diagram for cell 3 in 13 level inverter comprising S11-S15 switches with $\mathrm{mi}=0.81$ using PSO technique

Figure Error! No text of specified style in document. 15 shows the simulation results of the optimized output voltage waveform of the modified CHB-MLI using the PSO technique. It is shown that the optimized output voltage waveform of the inverter based on the PSO algorithm was smoother than that with the NR algorithm due to the inaccurate calculation of the switching angles using the NR technique in comparison with the PSO one. Figure Error! No text of specified style in document.16 shows the optimized harmonic spectrum of the output voltage waveform of the single-phase modified CHB-MLI using the PSO with its THD value equivalent to $5.16 \%$. Overall values of the switching angles and THD shown in Figure 17.

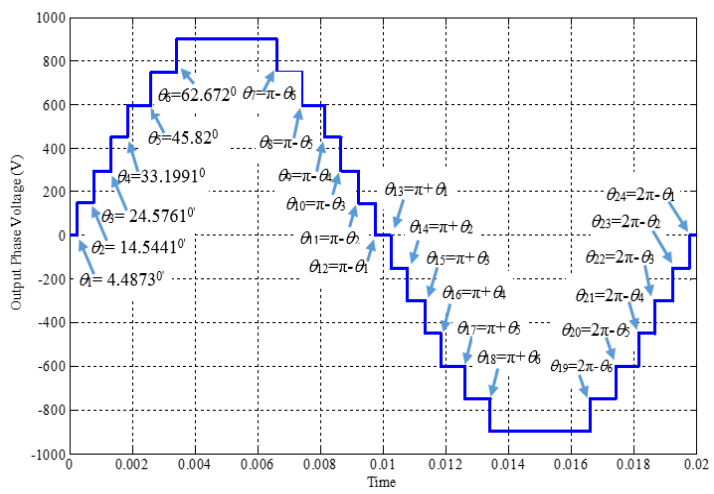

Figure Error! No text of specified style in document.15. Optimization of output voltage waveform of 13-level with $m_{i}=0.81$ using PSO technique

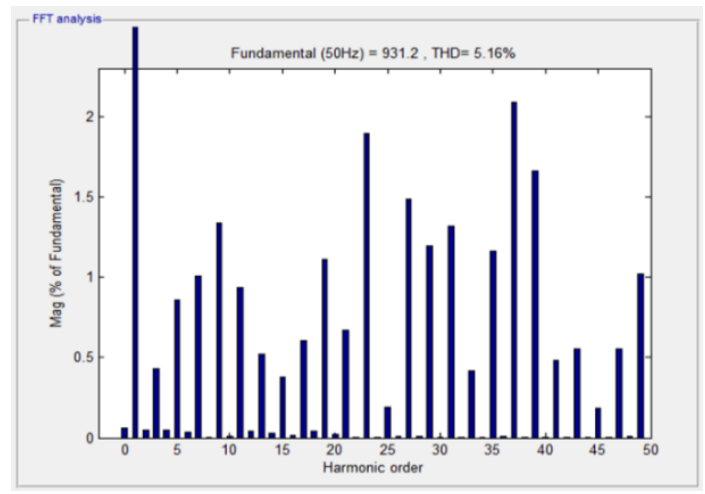

Figure 16. Harmonic spectrum of output voltage waveform of the modified CHB-MLIs with $\mathrm{Mi}=0.81$ using $\mathrm{PSO}$ technique 


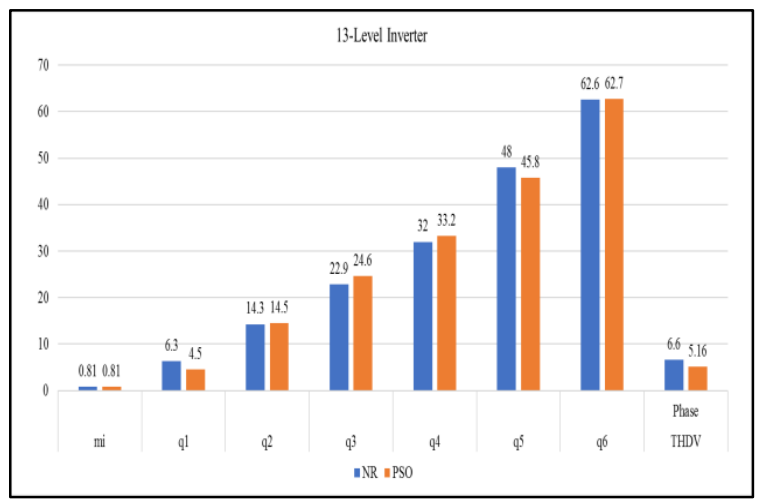

Figure 17. Overall values of the switching angles and THD for the output voltage of the modified CHB-MLI of 13-levels based on NR and PSO techniques

Table 2. Overall Values of $m_{i}$, Switching Angles and THD for Output Voltage of the Modified CHB-MLI for 13-levels based on NR and PSO Techniques

\begin{tabular}{ccccccccc}
\hline 13-level & $m_{i}$ & $\theta_{1}$ & $\theta_{2}$ & $\theta_{3}$ & $\theta_{4}$ & $\theta_{5}$ & $\theta_{6}$ & THD $_{\mathrm{V}}$ \\
\hline NR & 0.81 & 6.3 & 14.3 & 22.9 & 32.0 & 48.0 & 62.6 & 6.6 \\
PSO & 0.81 & 4.5 & 14.5 & 24.6 & 33.2 & 45.8 & 62.7 & 5.16 \\
\hline
\end{tabular}

\section{EFFICIENCY OF THE MODIFIED CHB-MLI}

Actually, the efficiency of the inverter simply can be defined as the process of converting the DC power into an $\mathrm{AC}$ power during the conversion of the power in the system, and there are power losses available, these losses would change as a heat, making the inverter heated, and causing reduction in its operational life time. The drop in the inverter output power controlled with both algorithms NR and PSO will cause its efficiency to be reduced as shown in Figure Error! No text of specified style in document.18, but the efficiency performance of the inverter under the PSO controller is better than the NR one due to effect of the optimization. The DC input power doesn't convert completely into AC output power; part of which is converted into losses. These losses are produced depending on the materials nature of inverter switches as well as the harmonic content, THD of its output. This makes inverter under the PSO control is better than the NR control.

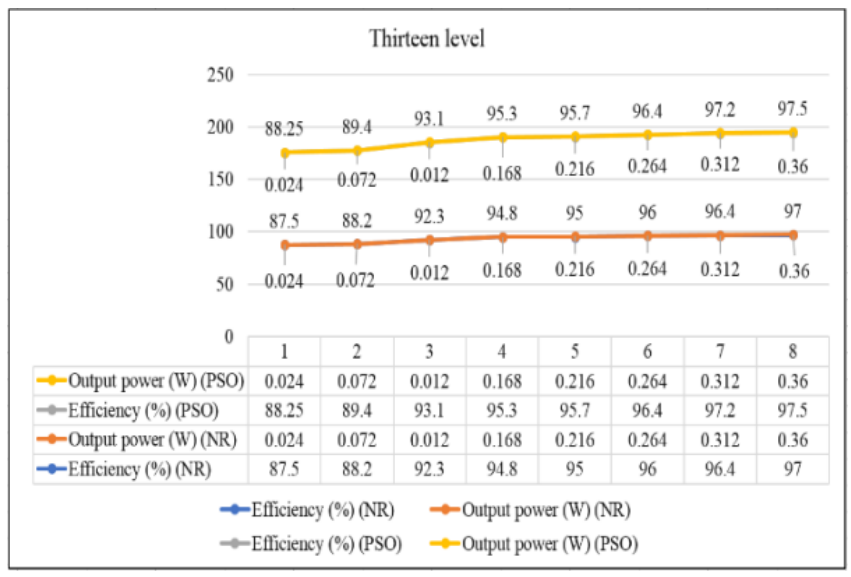

Figure 18. Efficiency of the 13-level modified CHB-MLI for versus technique PSO and NR

\section{CONCLUSIONS}

The simulation results showed that the higher level of the modified inverter will produce lower harmonics content in its output voltage waveform using the both NR and PSO techniques. However, the PSO technique produce lower content of harmonics (THD) compared to NR technique due to switching angles of the PSO technique is more accurate and thus, more efficient in eliminating lower order harmonics. Its proved that the proposed PSO technique produced the best switching angles. Voltage harmonics within an electrical power system 
will cause power line carrier disorder, which leads to long distance operation of switching devices, load control, and metering to be less precise.

\section{ACKNOWLEDGEMENTS}

This research is sponsored by the Fundamental Research Grant Scheme (FRGS) which the number is FRGS/1/2016/ TK04/FKE-CERIA/F00306. The authors wish to thanks to the Ministry of Education Malaysia for the funding to support this project and also to thanks to UTeM in providing the facilities and research environment. The authors would also to thank the Centre for Research and Innovation Management Universiti Teknikal Malaysia Melaka (CRIM-UTeM).

\section{REFERENCES}

[1] H. Rashid, Power electronics: circuits, devices, and applications. Pearson/Prentice Hall, 2004.

[2] M. Rasheed, R. Omar, and M. Sulaiman, "Optimization switching angle based on practical swarm optimization ( PSO) of A DSP-TMS320F2812 controlled for multilevel inverter," Int. J. Eng. Technol, vol. 7, no. 4, pp. 5666-5672, 2018.

[3] M. Rasheed, R. Omar, M. Sulaiman, and W. A. Halim, "Particle swarm optimisation ( PSO ) algorithm with reduced numberof switches in multilevel inverter ( MLI )," Indones. J. Electr. Eng. Comput. Sci., vol. 14, no. 3, pp. 1114-1124, 2019.

[4] M. Jones and I. N. W. Satiawan, "A simple multi-level space vector modulation algorithm for five-phase open-end winding drives," Math. Comput. Simul., vol. 90, pp. 74-85, Apr. 2013.

[5] S. K. Mondal, B. K. Bose, L. Fellow, and V. Oleschuk, "Space Vector Pulse Width Modulation of Three-Level Inverter Extending Operation Into Overmodulation Region," IEEE Trans. POWER Electron., vol. 18, no. 2, pp. 604-611, 2003.

[6] R. N. A. Krismadinata, H. W. Ping, and J. Selvaraj, "Elimination of Harmonics in Photovoltaic Seven-level Inverter with Newton-raphson Optimization," Procedia Environ. Sci., vol. 17, pp. 519-528, 2013.

[7] U. B. S. D, "Harmonic Orientation of Pulse Width Modulation," Power Eng. Electr. Eng., vol. 9, no. 1, pp. 29-34, 2011.

[8] A. Fri, R. El Bachtiri, and A. El Ghzizal, "A Comparative Study of Three Topologies of Three-phase (5L) Inverter for a PV System," Energy Procedia, vol. 42, pp. 436-445, 2013.

[9] O. Abdel-Rahim, H. Abu-Rub, and A. Kouzou, "Nine-to-Three Phase Direct Matrix Converter with Model Predictive Control for Wind Generation System," Energy Procedia, vol. 42, pp. 173-182, 2013.

[10] B. Boost, V. Current, S. Inverter, Q. Lei, S. Member, and F. Z. Peng, "Space Vector Pulsewidth Amplitude Modulation for a," vol. 29, no. 1, pp. 266-274, 2014.

[11] E. Babaei, M. F. Kangarlu, and F. N. Mazgar, "Symmetric and asymmetric multilevel inverter topologies with reduced switching devices," Electr. Power Syst. Res., vol. 86, pp. 122-130, May 2012.

[12] R. a Ahmed and S. Mekhilef, "New multilevel inverter topology with minimum number of switches," TENCON 2010 - 2010 IEEE Reg. 10 Conf., pp. 1862-1867, Nov. 2010.

[13] S. H. H. Ebrahim Babaei, "New multilevel inverter topology with minimum number of switches," IEEE Reg. 10 Annu. Int. Conf. Proceedings/TENCON, vol. 50, no. 11, pp. 1862-1867, 2010.

[14] S. H. Hosseini, M. F. Kangarlu, and A. K. Sadigh, "A New Topology for Multilevel Current Source Inverter with Reduced Number of Switches,” Electr. Electron. Eng. 2009. ELECO 2009. Int. Conf. on. IEEE, pp. 273-277, 2009.

[15] W. A. Halim and N. A. Rahim, "FPGA-based pulse-width modulation control for single-phase multilevel inverter," 2011 IEEE 1st Conf. Clean Energy Technol. CET 2011, pp. 57-62, 2011.

[16] J. J. Nedumgatt, D. V. Kumar, A. Kirubakaran, and S. Umashankar, "A multilevel inverter with reduced number of switches," 2012 IEEE Students' Conf. Electr. Electron. Comput. Sci. Innov. Humanit. SCEECS 2012, vol. 1, 2012.

[17] A. K. Al-Othman and T. H. Abdelhamid, "Elimination of harmonics in multilevel inverters with non-equal dc sources using PSO,” Energy Convers. Manag., vol. 50, no. 3, pp. 756-764, 2009.

[18] S. Sudha Letha, T. Thakur, and J. Kumar, "Harmonic elimination of a photo-voltaic based cascaded H-bridge multilevel inverter using PSO (particle swarm optimization) for induction motor drive," Energy, vol. 107, pp. 335-346, 2016.

[19] V. K. Gupta and R. Mahanty, "Optimized switching scheme of cascaded H-bridge multilevel inverter using PSO," Int. J. Electr. Power Energy Syst., vol. 64, pp. 699-707, 2015.

[20] B. Alamri, A. Sallama, and M. Darwish, "Optimum SHE for Cascaded H-Bridge Multilevel Inverters Using: NR-GA-PSO , Comparative Study,” pp. 1-10, 2015.

\section{BIOGRAPHIES OF AUTHORS}




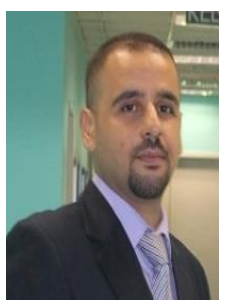

Mohammed Rasheed ${ }^{1}$ was born on July 1982 in Baghdad, Iraq. He received his degree in Electrical Engineering from University of Electrical and Electronic Techniques, Baghdad, Iraq in 2008 and obtained his M.S. in 2014 and Phd 2018 degree in Electrical Power Engineering from UTeM. He is currently a PhD, Post-Doctorate Research in Centre for Research and Innovation Management Universiti Teknikal Malaysia Melaka (CRIM-UTeM) in Department of Electrical Engineering, University Technical of Malaysia Melaka, Malaysia (UTeM). His research interests include power electronic.

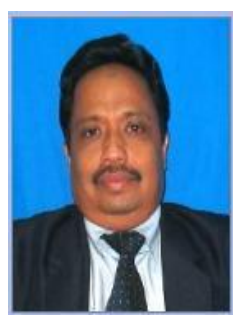

Rosli $\mathrm{Omar}^{2}$ received the degree in Electrical \& Electronics Engineering from University Technology Malaysia in 1991, M. Eng from University of Science Malaysia in 2001 and Ph.D. in Electrical from University of Malaya in 2011. He is currently an associate professor of the Faculty of Electrical Engineering, Technical University of Malaysia Melaka, Malaysia. His interests include power electronic, power quality and renewable energy.

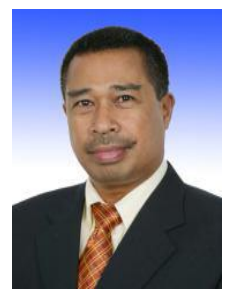

Marizan bin Sulaiman ${ }^{3}$ was born on April 16th, 1962 in Kuala Besut, Terengganu. He obtained his B.Sc., M.E.E. and Ph.D. in Electrical from University of Missouri-Columbia (UMC), USA in 1984, 1985 and 1989 respectively. He is currently a professor of the Faculty of Electrical Engineering, Technical University of Malaysia Melaka, Malaysia. His research interests include all areas of power systems, energy efficient systems, control and instrumentation, and e-learning.

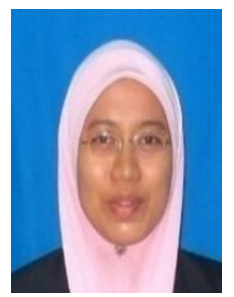

Wahidah Abd. Halim ${ }^{4}$ was born in Kuala Lumpur, Malaysia, in 1977. She received her B. Eng. degree (with Honors) in Electrical Engineering from the Universiti Teknologi Malaysia, Johor, Malaysia, in 2001, and her M.Sc. degree in Electrical Power Engineering from the Universiti Putra Malaysia, Serdang, Selangor, Malaysia, in 2005. She is presently working toward her $\mathrm{Ph} . \mathrm{D}$. degree at the University of Malaya, Kuala Lumpur, Malaysia. She is a Lecturer in the Faculty of Electrical Engineering, Universiti Teknikal Malaysia Melaka (UTeM), Melaka, Malaysia. 